*Doutor em Direito Empresarial pela Universidade Federal de Minas Gerais

Professor adjunto na Universidade Federal de Uberlândia-UFU

E-mail: cristianobrito@ufu.br

**Bacharel em Direito pela Faculdade Pitagoras

E-mail: mateusmartinsadvsea@ gmail.com

\section{A RESOLUÇÃO DO CONTRATO SOCIAL POR INADIMPLEMENTO NOS CONTRATOS COLIGADOS E O AFASTAMENTO DAS REGRAS DE DISSOLUÇÃO DA SOCIEDADE LIMITADA NOS NEGÓCIOS IMOBILIÁRIOS DE LOTEAMENTO}

\author{
TERMINATION OF ARTICLES OF ASSOCIATION \\ FOR BREACH OF RELATED CONTRACTS AND \\ DEPARTURE FROM THE RULES FOR WINDING UP \\ LIMITED LIABILITY COMPANIES IN REAL ESTATE \\ LAND LOT BUSINESS
}

\section{Cristiano Gomes de Brito* Mateus Martins Da Silveira**}

Como citar: BRITO, Cristiano Gomes de; SILVEIRA, Mateus Martins da. A resolução do contrato social por inadimplemento nos contratos coligados e o afastamento das regras de dissolução da sociedade limitada nos negócios imobiliários de loteamento. Scientia luris, Londrina, v. 25, n. 3, p. 109-124, nov. 2021. DOI 10.5433/21788189.2021v25n3p109. ISSN: 2178-8189.

Resumo: O presente trabalho tem por objetivo analisar a coligação contratual entre tipos jurídicos contratuais e o contrato social que constitui sociedade limitada, assim como sua resolução pelo inadimplemento em contrato a ele coligado, afastando as regras de dissolução e liquidação de sociedade no negócio imobiliário de loteamento. Propor-se-á a aplicação da resolução da sociedade pelo inadimplemento do sócio em contrato coligado, com o afastamento das regras societárias de dissolução e liquidação, privilegiando as disposições contratuais firmadas entre as partes.

Palavras-chave: Contrato. Sociedade Limitada. Coligação Contratual. Interpretação. Contrato Social. Imobiliário. Dissolução. Loteamento

Abstract: The objective of this paper is to analyze contract
relationship between legal contract types and the articles of
association that constitute limited liability companies, as well
as their termination for breach of a related contract, departing
from the rules for liquidation and winding up of a company in
real estate land lot business. We will propose the enforcement of
company termination for partner breach of related contract, with 
departure from the corporate rules for liquidation and winding up, privileging the contractual provisions signed between the parties.

Keywords: Contract. Limited Liability Company. Contract Relationship. Interpretation. Articles of Association. Real Estate. Liquidation. Land Lots. 


\section{INTRODUÇÃO}

O direito e seus institutos não conseguem acompanhar a vertiginosa modernização das relações humanas. Determinado contrato que antes era suficiente a regulamentar vínculo entre as partes, comumente passa a ser apenas fragmento de um negócio maior e mais complexo.

A evolução do homem e de suas relações dentro da sociedade e do ordenamento jurídico sempre esteve acompanhada da evolução contratual como mecanismo de regulação da economia, comércio e da própria propriedade, de modo que a circulação de riquezas, produtos e serviços, com o respaldo da segurança contratual, tem garantido negócios cada vez mais complexos, reclamando ferramentas jurídicas mais complexas e sofisticadas.

Como uma resposta à necessidade de adaptação dos institutos jurídico-contratuais à realidade dos negócios jurídicos é que surge a teoria da coligação contratual, que passa a tratar da necessidade de compreensão da aplicação e interpretação conjunta de vários tipos contratuais vinculados.

No presente estudo será abordado sua origem na doutrina internacional, bem como sua formação e identificação e os elementos específicos à sua caracterização, acompanhado das hipóteses de coligação. Em um segundo momento, tratar-se-á da interpretação da coligação contratual, bem como as diretrizes e critérios à disposição do intérprete para que possa extrair além do vínculo, o efetivo e correto produto da interpretação dos contratos coligados entre as partes.

Destaca que não serão exauridos todos os temas a respeito da coligação contratual e nem de todos os liames que circundam sua interpretação, mas atentar-se-á à análise da possibilidade de coligação contratual entre o contrato social que constitui sociedade limitada e outros tipos contratuais, bem como a hipótese de extinção do primeiro pelo inadimplemento e rescisão de outro à ele coligado e a afastabilidade das regras societárias que envolvem a dissolução e liquidação da sociedade limitada.

Isto porque, quando determinado contrato não é mais suficiente para regular a relação entre as partes e demanda a adaptação e junção com outro ou outros tipos contratuais, ligados por um nexo com origem no próprio fim negocial objetivado pelas partes, não haverá que se falar em aplicação isolada das regras e disposições previstas apenas para um dos contratos quando da resolução do negócio.

Ressalta que a aplicação da teoria da coligação contratual tem se mostrado cada vez mais presente no ordenamento jurídico brasileiro, de modo que é fundamental tratar do tema, especialmente envolvido dentro do direito societário, demandando conhecimento de advogados, juízes e juristas em geral.

\section{CONTRATOS COLIGADOS}

O contrato, como negócio jurídico que cria, modifica e extingue direitos, mediante a 
livre manifestação de vontade das partes, é o vetor de desenvolvimento econômico que permite a circulação de riquezas, estabelecendo direitos e deveres, que vem se aprimorando e evoluindo de acordo com as necessidade dos negócios modernos, ao ponto de se tornar, em muitos casos, inviável a celebração de único contrato para abarcar as necessidades dos contratantes, necessitando de outros que lhe deem suporte jurídico a viabilizar sua realização.

Diante dessa necessidade, surgiram as figuras de vinculação de contratos a outros, tornando-os dependente, como nos casos dos contratos coligados, mistos, dentre outros.

Compreende-se que os contratos coligados são aqueles em que mesmo autônomos por essência, apresentam entre si relação de interligação, de modo a produzir algum efeito jurídico aos demais.

Comumente, utiliza-se as expressões "contratos conexos", "contratos coligados" e "grupos de contratos" sem qualquer distinção. Entretanto, existe certa predominância da expressão “contratos coligados" conforme adotada por Francisco Paulo de Crescenzo Marino (2009, p. 43) e inspirada na doutrina italiana que, por sua vez, garante críticas às nomenclaturas em paralelo, sem relevância para o presente trabalho.

Neste artigo, adota-se a nomenclatura de "contratos coligados" por delimitar as hipóteses de união juridicamente relevantes do ordenamento, enquanto que as demais (contratos conexos e grupos de contratos) englobariam diversas outras hipóteses de conexão e união entre contratos que não a coligação contratual propriamente dita, como explica Carlos Nelson Konder (2006, p. 189-225).

Para Pontes de Miranda (1962, p. 368) decorre a ligação entre dois ou mais negócios jurídicos concluídos em tempos diferentes - portanto, também em instrumentos diferentes - e que um dependa do outro, ou cada um dependa de qualquer dos outros. ${ }^{1}$

Para Rodrigo Xavier Leonardo (2016, p. 459), trata-se da pluralidade contratual acompanhada de relações jurídicas contratuais estruturalmente distintas, mas ligadas e que compõe uma mesma relação econômica, destacando ainda a potencialidade das consequências no plano da validade (influência recíproca de invalidade entre os contratos) e no plano da eficácia.

Laís Bergstein (2017, p. 159-183) prefere definir o termo "coligação", como sendo a ligação existente entre contratos e relações jurídicas diferentes, mas que juntas cooperam para uma operação econômica unificada.

Diante da ligação entre os contratos, seus vínculos podem decorrer da lei, por ato voluntário das partes ou em decorrência natural dos vários tipos de obrigações decorrentes de um negócio jurídico.

$\mathrm{Na}$ ex lege, o vínculo contratual decorre da expressa previsão legal, seja pela referência direta à coligação ou por meio da previsão de um de seus efeitos.

Já a coligação natural, deriva dos desdobramentos naturais do negócio jurídico celebrado pelas partes, em que naturalmente se faz necessária a celebração de outros contratos a fim de dar 1 No Brasil, o tema já foi tratado e reconhecido pelo Supremo Tribunal Federal em 1977 (RE/PR 78162). No julgamento do Recurso Extraordinário 78162 - PR, tratou de coligação contratual em contrato de promessa de compra e venda mercantil e comodato firmado entre distribuidoras de combustível. À época entendeu-se que ambos os contratos compunham uma unidade atípica, de modo a afastar a multa contratual de um dos contratos pelo inadimplemento. 
efetividade e utilidade ao acordo celebrado pelas partes, isto é, o vínculo de coligação entre os contratos dar-se-á pela própria natureza do negócio e dos tipos contratuais firmados entre as partes.

Por fim, a voluntária se caracteriza quando os contratos celebrados pelas partes forem independentes entre si e o vínculo entre eles decorrer exclusivamente da operação, relação e vontade das partes.

Assim, haverá coligação "voluntária" nas hipóteses em que o nexo dos contratos não deriva da lei e nem da natureza acessória de um dos contratos, mas sim da manifestação das partes em celebrar, em decorrência do acordo de vontade, vários tipos de contrato, que se coligarão. ${ }^{2}$

Na coligação voluntária, assevera Francisco Paulo de Crescenzo Marino (2009, p. 106), na doutrina de Giorgianni, que nestes casos, pressupõe a existência de um elemento objetivo e subjetivo. O primeiro seria equivalente ao nexo econômico e funcional entre os negócios firmados pelas partes, enquanto o segundo é a intenção de coordenar os contratos em direção de um escopo comum.

No presente estudo, haverá coligação voluntária (não necessariamente expressa) nos negócios imobiliários de incorporação imobiliária ou loteamento urbano, em que as partes (proprietário da área a ser loteada e incorporadora, que realiza o desenvolvimento imobiliário) firmam diversos contratos para um único fim econômico e negocial, in casu de parceria imobiliária coligado à contrato de constituição de sociedade limitada para a efetiva execução das obras do empreendimento.

Do desdobramento das espécies de coligações, verifica-se a condição para sua caracterização, quais sejam, a pluralidade contratual e nexo causal.

A pluralidade contratual, refere-se a existência de dois ou mais tipos contratuais que unirse-ão por meio de determinado nexo. ${ }^{3}$ Já o nexo pressupõe a existência dos contratos como figuras autônomas estruturalmente, ou seja, onde cada um conserva suas regras e disposições próprias. Do contrário, falar-se-ia em unidade contratual ${ }^{4}$.

Esse nexo decorre de manifestação, expressa ou tácita, das partes ao celebrarem o negócio jurídico, na qual haverá vinculação entre os contratos celebrados, em que a vontade das partes não poderá ser interpretada pela análise de um ou outro contrato celebrado, mas sim, por todos os contratos celebrados pelas partes, privilegiando o fim dado ao negócio, como previsto nos artigos 170 e 883 do CC.

Daí, não necessariamente, o eventual descumprimento de um contrato acarretará tão somente os efeitos jurídicos deste contrato, mas poderá irradiar em outros contratos em que as

\footnotetext{
2 Para fins didáticos, esclarece-se que a coligação voluntária pode ser expressa ou implícita. Por esse motivo é que a diferencia da coligação natural, conforme acima explanado, visto que em alguns casos pode haver confusão entre as classificações. Assim, quando a origem do vínculo contratual for a complexidade da operação e do negócio realizado pelas partes, estar-se-á diante da coligação voluntária, e quando o vínculo for decorrente da natureza do contrato (acessório decorre e segue o principal, por exemplo), falar-se-á em coligação natural.

3 A propósito de evitar a confusão entre contratos coligados (pluralidade contratual) e contratos complexos e contratos mistos (unidade contratual). Os contratos complexos são aqueles em que, subjetivo, volitivo ou objetivamente, haverá complexidade quanto aos polos contratuais, manifestação de vontade e/ou pluralidade de prestações.

4 Exemplo de conservação da estrutura contratual, ainda que coligado e ligado por um nexo, é a hipótese do contrato de locação coligado com o de fiança como garantia do negócio (não confundir com o caráter de contrato principal e acessório). Em que pese estarem, em regra, num mesmo instrumento contratual, cada um mantém suas características que lhes são próprias e produz os efeitos que deles se esperam.
} 
partes vem cumprindo suas obrigações.

É este fim desejado e projetado pelos contratantes o nexo responsável por (co)ligar os diversos tipos contratuais firmados pelas partes, e ao mesmo tempo em que embasa, também justifica a teoria dos Contratos Coligados, da qual passará a verificar a forma de se interpretar e aplicar.

\section{A INTERPRETAÇÃO DOS CONTRATOS COLIGADOS}

O presente trabalho aborda a perspectiva interpretativa da coligação voluntária, a fim de se delimitar ao propósito que se destina, qual seja, verificar a possibilidade de afastamento de norma prevista no Código Civil por meio da aplicação da teoria da coligação contratual, pressupondo a existência de coligação voluntária.

O CC prevê regras interpretativas dos contratos, as quais são plenamente aplicáveis aos contratos coligados, conforme se extrai dos artigos 112 e 113, prevendo que nas declarações de vontade se atenderá mais à intenção nelas consubstanciada do que ao sentido literal da linguagem, e que nos negócios jurídicos devem ser interpretados conforme a boa-fé e os usos do lugar de sua celebração.

Por isso que a própria lei civil prevê a prevalência da vontade das partes em detrimento da literalidade da linguagem, assim como outros critérios interpretativos.

Os dispositivos contratuais não devem ser interpretados de forma restrita, assim como as palavras e orações que os compõem, mas estas devem levar em consideração todo o dispositivo e este, por sua vez, deve ser analisado sob a perspectiva de todo o contrato. Deve-se identificalos dentro do contexto das demais disposições do contrato analisado, sob pena de interpretar equivocadamente o instrumento contratual.

$\mathrm{Na}$ hipótese dos contratos coligados, não é suficiente observar o conjunto das cláusulas dentro do contrato, devendo ser interpretadas de forma sistemática aos demais contratos a ele coligados. Ou seja, expande-se a interpretação sistemática para além da figura individual de determinado contrato, passando a considerar todos os contratos vinculados de alguma forma. Segundo Marino (2009, p. 148) é dever do intérprete, quando identificada a existência de vinculação contratual de alguma forma, interpretar cada um dos contratos, ainda que autônomos entre si, valendo-se do outro como meio de interpretação.

Nesse último, o intérprete deve se aprofundar ainda mais seu conhecimento a respeito do negócio havido entre os contratantes, assim como das circunstâncias e condições que cercaram e justificaram a manifestação de vontade na forma como feito no instrumento contratual. Só assim será capaz de realmente extrair das cláusulas contratuais o âmago da declaração negocial.

Os critérios interpretativos apresentados e considerados pelo atual ordenamento jurídico para os contratos em geral, podem ser aplicados aos contratos coligados, entretanto, alguns se destacam como melhores à elucidação do negócio e eventual lide instaurado entre os contratantes, 
como a interpretação sistemática.

Isto porque, quando da coligação contratual, o fim desejado e buscado pelas partes (que também será considerado um dos critérios interpretativos) somente poderá ser alcançado por meio da análise sistemática entre cláusulas e entre contratos. Diversos contratos e dispositivos contribuem e cooperam entre si para o alcance de um determinado objetivo, por isso, a intenção finalística somente será palpável por meio da sistematização do conteúdo jurídico e fático de todo o negócio.

Não somente o fim do negócio, mas por meio da interpretação sistemática é possível observar e identificar eventual vinculo e até mesmo a pluralidade contratual ao caso tratado. Isto porque, o nexo contratual poderá ser reconhecido em elementos fáticos ou jurídicos comuns aos contratos interpretados.

Nesse sentido, explica Francisco Paulo de Crescenzo Marino (2009, p. 148) que, muito embora cada um deles mantenha a sua individualidade e o próprio conteúdo, muitas cláusulas contratuais somente poderão ser compostas a partir de elementos presentes nos textos de todos os contratos envolvidos. Com efeito, não é raro que cláusulas de um contrato sejam "completadas" por dispositivos contidos em contrato à ele coligado.

Por isso, destaca ainda que, para prevalecer o disposto no art. 112 do Código Civil, qual seja, que a vontade das partes se sobressaia ao sentido literal das cláusulas, é mandamental a realização de interpretação sistemática, visto que a análise de um ou de outro contrato coligado de forma isolada pode deturpar a intenção e a finalidade perseguida pela(s) parte(s) do negócio. ${ }^{5}$

Segundo Haroldo Malheiros Duclerc Verçosa (2014, p. 470), a interpretação sistemática dos contratos sempre foi um dos critérios a serem observados na interpretação subjetiva dos contratos. Entretanto, ali se fala em sistemática dentro de uma mesma unidade contratual, enquanto que nos contratos coligados deve-se observar de forma mais abrangente, a fim de compreender tanto a interpretação sistemática entre as cláusulas do tipo contratual individual, como entre este e seus coligados.

Embora a atividade interpretativa possa ser considerada como um processo único, por questões didáticas a doutrina a subdivide em duas fases, denominadas de interpretação subjetiva e a outra de interpretação objetiva.

Quanto à primeira, prossegue o mencionado Autor, tratando de interpretação contratual de forma geral (contratos não coligados) exemplifica o rol dos critérios a serem observados, quais sejam: (i) observância do sentido literal das palavras; (ii) aferimento da intenção comum das partes; (iii) interpretação sistemática das cláusulas; (iv) exame das expressões gerais usadas no contrato; (v) estudo das indicações exemplificativas.

\footnotetext{
5 Os tribunais superiores acompanham o entendimento doutrinário a respeito da interpretação sistemática dos contratos, considerando a convergência dos interesses dos contratantes a pontos comuns, reforçando a tese apresentada neste trabalho Vide item 5 da ementa do citado julgado: A interdependência, a conexidade ou a coligação dos contratos firmados pelas partes (cisão de empresa, acordo de acionistas e contrato de locação) resultam claras e evidentes, haja vista a unidade dos interesses representados, principalmente os de natureza econômica, constituindo esse plexo de avenças o que a doutrina denomina de contratos coligados; em caso assim, embora possível visualizar de forma autônoma cada uma das figuras contratuais entabuladas, exsurge cristalina a intervinculação dos acordos de vontade assentados, revelando a inviabilidade da revisão estanque e individualizada de apenas um dos pactos, quando unidos todos eles pela mesma função econômica comum (BRASIL, 2012).
} 
Nem todos esses critérios devem ser aplicados às hipóteses de interpretação de contratos coligados. Os principais deles, que seriam a busca pela intenção comum das partes e interpretação sistemática das cláusulas e contratos já foram abordados. Por outro lado, na coligação contratual a interpretação objetiva se mostra muito mais eficiente, justificando assim a abertura de tópico próprio dentro deste trabalho.

O caráter interpretativo do princípio da boa-fé é consagrado expressamente no art. 113 do $\mathrm{CC}$, ao estabelecer que os negócios jurídicos devem ser interpretados conforme a boa-fé e os usos do lugar de sua celebração. O princípio, por sua vez, pode ser divido em boa-fé subjetiva ou objetiva, entretanto, para o exercício interpretativo, deve-se considerar apenas este último.

\section{DA RESOLUÇÃO DO CONTRATO SOCIAL PELO INADIMPLEMENTO EM CONTRATO VINCULADO E AS REGRAS DE DISSOLUÇÃO E LIQUIDAÇÃO DE SOCIEDADE LIMITADA}

Pela liberdade que o tipo contratual proporciona, os sócios se valem da prerrogativa para adequar o modelo societário ao negócio ou à atividade pretendida para exercício, lançando mão de um leque de opções, tanto no contrato social como em acordo parassociais, para disciplinar da melhor forma possível a relação entre os sócios e o negócio.

A sociedade limitada é constituída por meio do contrato social, regida pelo $\mathrm{CC}$, em que sua natureza de contrato plurilateral, privilegia a autonomia de vontade das partes para estabelecer as regras de constituição, administração e extinção da sociedade.

Prevê o CC, no art. 1.102, que dissolvida a sociedade e nomeado o liquidante, procedese à sua liquidação, ressalvado o disposto no ato constitutivo ou no instrumento da dissolução. Compreende-se desse dispositivo a livre manifestação das partes quanto as regras de dissolução e liquidação da sociedade, privilegiando a autonomia de vontade dos sócios, não sendo matéria de ordem pública a impedir seu regramento pelas partes, com sua coligação ao outro contrato, como de parceria imobiliária.

$\mathrm{Na}$ sociedade limitada, por sua natureza de contrato plurilateral, as relações entre os sócios são constituídas por um contrato, um ajuste de suas vontades, sob a regência dos princípios do direito contratual e da autonomia de vontade das partes.

\subsection{Da Coligação Contratual Aplicada aos Contratos Sociais no Negócio Imobiliário DE LOTEAMENTO}

A coligação contratual não é restrita a nenhum tipo contratual, de modo que para sua existência e aplicação, consideram-se os elementos necessários à sua configuração, conforme já delineado neste trabalho, especialmente quanto à pluralidade contratual e nexo contratual.

Presente os elementos característicos da coligação contratual, o que somente será verificado e apurado no caso concreto, é plenamente possível a coligação de determinado tipo 
contratual com o contrato social que constitui a sociedade limitada. Nesses casos, a sociedade será considerada apenas parte do negócio em si, cercando e vinculando-se a outros contratos, em regra pela vontade das partes (implícita ou explícita).

Nessa hipótese, o contrato social deve ser visto e interpretado, não somente pelas regras do direito societário, mas sim sob a ótica sistemática com os demais contratos que a ele se coligam, valendo-se dos critérios interpretativos como o fim contratual e a boa-fé objetiva.

O presente estudo, então, restringe-se os negócios imobiliários de loteamento urbano, em que a complexidade do empreendimento demanda às partes a celebração de tipos contratuais diversos, mas que juntos, cooperam para um único objetivo.

Isto porque, a realização desses empreendimentos se dá por meio do contrato de parceria imobiliária, seguido da constituição de determinado tipo societário (em alguns casos com propósito específico definido) entre outros tipos contratuais para a concretização do negócio.

Em regra, comumente a sociedade é constituída sob a forma de limitada, em que um dos sócios contribui para o negócio com o imóvel a ser loteado, e o faz integralizando sua quota parte na sociedade com o bem, enquanto o outro, por sua vez, se compromete a realizar as obras de parcelamento do solo e de infraestrutura do loteamento, também como forma de integralizar sua participação na sociedade.

Para tanto, é comum que os contratantes interessados no negócio realizem negociações prévias à constituição da sociedade, a fim de levantar e definir valores de investimento e gastos com o empreendimento, as obrigações de cada parte, participação de cada contratante no produto do loteamento ou da incorporação, forma de comercialização, projeção do preço final do lote ou unidade imobiliária, acordo de não concorrência, entre outros, por meio do contrato de parceria imobiliária.

Após, os contratantes constituem sociedade limitada, para que as obras de construção, infraestrutura do empreendimento e outros contratos sejam realizados e firmados por meio da personalidade jurídica da sociedade limitada.

Analisando sob a perspectiva da coligação contratual, além da pluralidade de contratos - considerando a existência ao menos do contrato de parceria imobiliária e do contrato social responsável pela constituição da sociedade - existe nítido vínculo entre os tipos contratuais.

Isto porque, a intenção fim das partes com o negócio unifica a relação entre os contratos, tornando-os uma estrutura unitária e funcional. Não se pretende a simples constituição de uma sociedade para o exercício de determinada atividade de forma organizada, em verdade, os contratantes buscam fim objetivo e específico, qual seja, a realização do empreendimento imobiliário de loteamento.

Por outro lado, também não se justificaria o simples acordo das partes sobre as despesas e forma jurídica e comercial do empreendimento, como é feito por meio do contrato de parceria imobiliária se dali não resultasse a efetiva realização do negócio, o que acontece por meio da constituição da sociedade.

É evidente que mesmo se tratando, a princípio, de figuras autônomas, existe nexo 
contratual entre ambos os contratos, visto que, não firmando um, não teriam as partes motivo para firmarem o outro. Em verdade, os tipos contratuais cooperam em conjunto para um único fim projetado pelos contratantes, por isso, aplicar-se-á a teoria da coligação contratual.

Assim, considerando a possibilidade e a hipótese de coligação contratual entre determinado tipo contratual (aqui o contrato de parceria imobiliária) e o contrato social da empresa, nos casos em que os contratantes assumirem determinadas obrigações por meio de outros tipos contratuais, recíprocas ou não, para a realização e conclusão do empreendimento (fim do contrato), o inadimplemento dessas obrigações implicará na possibilidade da parte inocente ter por rescindido todos os demais contratos, inclusive o contrato social.

\subsection{Da Resolução do Contrato Social pelo Inadimplemento de Contrato Coligado}

Quando o contrato de constituição da sociedade estiver subordinado ao negócio firmado entre as partes e coligado a outros contratos, o inadimplemento da parte em algum destes poderá ser estendido aos demais.

É questão atinente ao plano da eficácia e de sua repercussão aos contratos coligados a mora e o inadimplemento absoluto de obrigação prevista em qualquer dos contratos. Salvo a hipótese de cláusula de inadimplemento cruzado (cross-default), deve ser considerado a importância da prestação inadimplida dentro do fim negocial almejado pelas partes conforme Francisco Paulo de Crescenzo Marino (2009, p. 198), que ao asseverar que a determinação do alcance do inadimplemento dependerá, então, da avaliação dos seus efeitos em relação a cada um dos contratos e, principalmente, frente à realização do fim concreto e ao equilíbrio entre as prestações dos diversos contratos. ${ }^{6}$

Pondera Rui Rosado de Aguar (2004, p. 90) que, diante de contratos coligados de mesma importância, a resolução de um repercutirá no outro em três casos: quando (i) demonstrar que um não teria sido firmado sem o outro; (ii) quando a impossibilidade de um determina a do outro e (iii) quanto o incumprimento de um afeta o interesse que o credor poderia ter no cumprimento do outro.

No presente estudo, em que o contrato de parceria imobiliária dita as regras e as consequências do negócio firmado entre as partes, e a constituição da sociedade se dá como um meio à realização do fim contratual previamente objetivado, são considerados como contratos recíprocos, no qual, a prestação de uma das partes é o cumprimento da obrigação assumida em outro contrato coligado ao primeiro ${ }^{7}$. A consequência do inadimplemento da prestação assumida em um contrato é de prejudicialidade total do conjunto contratual.

Isto porque, ambos os tipos contratuais são firmados com um único fim e passarão a ser considerados como uma unidade contratual. Assim, não se justifica a manutenção de um na

\footnotetext{
6 Pode acontecer que a prestação onerosa assumida em um contrato seja correspondente à vantagem garantida em outro, de tal sorte que a falta de um poderá abalar o equilíbrio que o conjunto de contratos garantia (AGUIAR JÚNIOR, 2004, p. 90).

7 Onde o desenvolvedor imobiliário, quem assume a responsabilidade de realizar as obras de infraestrutura do negócio imobiliário, se compromete na parceria imobiliária, a fazê-las por meio da integralização do capital social da sociedade empresária constituída especificamente para tal fim.
} 
hipótese de rescisão do outro. O descumprimento do contrato de parceria por alguma das partes justifica, de todas as formas, a extensão deste inadimplemento também para o contrato social da sociedade constituída em prol do negócio almejado pelas partes no contrato de parceria imobiliária.

Seja porque um contrato não teria sido firmado sem o outro, visto que não há motivos que justifiquem a associação dos contratantes por meio de constituição de determinada sociedade se não fosse para executar o empreendimento imobiliário contratado por meio do contrato de parceria imobiliária. Por outro lado, pode ser que as partes sequer firmariam a parceria se não acordassem em executá-la por meio da constituição de uma sociedade empresária.

O inadimplemento em qualquer dos contratos implicará na impossibilidade de cumprimento do outro, considerando a interdependência existente entre ambos os tipos contratuais. A parceria imobiliária é o fundamento e justificativa pela qual as partes constituíram sociedade empresária para realizar o negócio imobiliário e o inadimplemento desta, impossibilitará a continuidade da sociedade.

A consequência do descumprimento pelo contratante das obrigações assumidas no contrato de parceria imobiliária, será, além da possibilidade de rescisão da parceria pelo sócio inocente, também a rescisão do contrato social que constituiu a sociedade limitada para realização do negócio.

Logo, se não existe mais acordo quanto a forma de realização do empreendimento, quanto às responsabilidades das partes e concorrência para os lucros e perdas (dentre outros), a sociedade criada para aquele único propósito com o fim contratual de realização da incorporação imobiliária ou loteamento, não mais se justifica e nem serve ao objetivo pela qual foi contratada ${ }^{8}$.

Por isso, na hipótese trabalhada, o descumprimento e rescisão do contrato de parceria imobiliária implicará na extensão desse inadimplemento e da própria rescisão ao contrato de constituição da sociedade, contaminando-o pela inviabilidade do fim contratual objetivado pelas partes, uma vez que ambos os contratos cooperavam em conjunto como se uma unidade fossem.

É importante ainda compreender que no caso da coligação contratual, seja ela qual for, não necessariamente será aplicado, quando do inadimplemento ou resolução, todo o regramento de cada um dos tipos contratuais, de modo que, na situação proposta, quando se estendido o inadimplemento da parceria imobiliária ao contrato social. Falar-se-á em derrogação de parte do

\footnotetext{
8 A jurisprudência acompanha o entendimento de que o fim contratual do negócio e dos contratos coligados tem relevância suficiente para que os contratos se afetem reciprocamente, levando em consideração as circunstâncias do negócio e da relação entre as partes. Nesse sentido, o STJ decidiu que "embora mantida a individualidade jurídica de cada um dos contratos, eles são coligados, interdependentes e reciprocamente condicionados na sua existência, representando uma unidade econômica, de tal sorte que a desconstituição de um implica a do outro. Para a Corte, é evidente que a causa da assunção da dívida foi a locação do imóvel que, afinal, acabou rompida, não havendo interesse autônomo na confissão. Por outro lado, a assunção do débito foi condição para a locação, apresentando-se mesmo como parte do preço desta. Confira-se a ementa: EXECUÇÃO FUNDADA EM CONTRATO DE CONFISSÃO DE DÍVIDA COLIGADO A CONTRATO DE LOCAÇÃO DE IMÓVEL. DESCONSTITUIÇÃO DO PRIMEIRO NEGÓCIO QUE IMPLICA A DO SEGUNDO. INEXIGIBILIDADE DO TÍTULO EXECUTIVO. INTERPRETAÇÃO DE CLÁUSULAS CONTRATUAIS. REEXAME DE FATOS E PROVAS. IMPOSSIBILIDADE. DECISÃO MANTIDA. RECURSO DESPROVIDO. [...] 2. O Tribunal de origem concluiu pela inexigibilidade do título exequendo, porque evidenciado nos autos que o contrato de confissão de dívida, consistente na obrigação de indenização de benfeitorias realizadas pelo antigo locatário, era coligado e subordinado ao contrato de locação do imóvel, de modo que a resolução deste levou à ineficácia do contrato de assunção de dívida. 3. A conclusão do acórdão recorrido foi extraída a partir da análise das cláusulas contratuais e das circunstâncias fáticas do negócio, as quais revelaram que a assunção de dívida era um subcontrato e a locação um contrato-base, com coligação contratual, estando o primeiro subordinado ao segundo. [...] (BRASIL, 2018b).
} 
regime societário.

Isto porque, quando a resolução da sociedade se der em decorrência do descumprimento de contrato coligado, conforme citado, aplicar-se-á de forma global e sistemática as previsões e os dispositivos dos contratos vinculados entre si, o que poderá afastar as regras do direito societário quanto à dissolução e liquidação da sociedade, conforme trabalhado adiante.

Para Arnaldo Rizzardo (2004, p. 32) as partes são obrigadas a dirigir a manifestação da vontade dentro dos interesses que as levaram a se aproximarem, de forma clara e autêntica, sem o uso de subterfúgios ou intenções outras que as não expressas no instrumento formalizado. A segurança das relações jurídicas depende, em grande parte, da probidade e da boa-fé, isto é, da lealdade, da confiança recíproca, da justiça, da equivalência das prestações e contraprestações da coerência e clarividência dos direitos e deveres.

Explica Carlos Roberto Gonçalves (2007, p. 36), a boa-fé é tanto forma de conduta (subjetiva ou psicológica) como norma de comportamento (objetiva). Nesta última acepção, está fundada na honestidade, na retidão, na lealdade e na consideração para com os interesses do outro contratante, especialmente no sentido de não lhe sonegar informações relevantes a respeito do objeto e conteúdo do negócio.

Em razão do princípio da boa-fé, surge para as partes deveres anexos aos contratos, como o dever de informar, lealdade, confiança, probidade etc. Por tal razão, quando da celebração do contrato, é essencial que as partes se expressem de forma clara e objetiva seus interesses, bem como suas intenções e condições. ${ }^{9}$

Ademais, é da essência do Código Civil a manutenção da vontade das partes nos contratos, em face do princípio da conservação do negócio, mesmo quando afetado por nulidade

\subsection{Do Afastamento das Regras de Direito Societário na Resolução da Sociedade} LIMITADA

Identificada a existência de coligação contratual entre o contrato social que constitui a sociedade limitada e outros tipos contratuais firmados para a realização de um negócio jurídico com único fim contratual, é importante definir e determinar o regramento aplicável à resolução deste contrato social.

Quanto ao regramento, cumpre destacar que o próprio instituto da coligação contratual pressupõe a existência de mais de um regramento aplicável ao caso, considerando a pluralidade contratual envolvida no negócio e o interesse finalístico entre as partes.

Isso implicará na derrogação de parte ou até da totalidade de determinado regime contratual $^{10}$, conforme ensina Francisco Paulo de Crescenzo Marino (2009, p. 182), ao afirmar que a coligação contratual é importante fator de derrogação dos regimes típicos. À exceção dos tipos contratuais acessórios (v.g., contrato de fiança), o tipo normal ou empírico, extraído da própria regulação que lhe corresponde, é o tipo "puro", desvinculado de outros contratos.

\footnotetext{
$9 \mathrm{Na}$ análise do princípio da boa-fé dos contratantes, devem ser examinadas as condições em que o contrato foi firmado, o nível sociocultural dos contratantes, o momento histórico e econômico, porque é ponto de interpretação da vontade contratual.

10 Merece a observação de que os tipos contratuais acessórios, por si só, já se vinculam ao regime do tipo contratual determinado como principal, de modo que, independentemente da existência de coligação contratual, prevalece o princípio de que "o acessório segue o principal".
} 
A derrogação de determinado regramento pode ser justificada pela própria autonomia, liberdade contratual e a vontade das partes, ou revelada por meio da intepretação dos contratos coligados, por meio dos critérios interpretativos já delineados neste trabalho.

Na problemática proposta, via de regra, o termo correto para tratar da extinção da sociedade é a sua dissolução total ou parcial, conforme previsão legal ${ }^{11}$. Entretanto, as partes podem optar em não adotar estas regras, afastando-as do direito societário quando da resolução do contrato social firmado como parte coligada a um fim negocial, como nos negócios imobiliários urbanísticos.

À medida que os contratos se sujeitam uns aos outros, não mais se aplica isoladamente o regime jurídico de um determinado tipo contratual, sob pena de não extrair o que realmente seria o produto do dispositivo contratual, visados pelas partes.

Portanto, o contrato de sociedade, quando coligado com outro, sujeitará sua resolução às regras previstas e extraídas por meio da interpretação sistemática e global do negócio.

Essa influência recíproca repercute na aplicação das regras contratuais firmadas entre as partes em detrimento de outras previstas legalmente para o tipo contratual considerado de forma isolada, em face do elevado grau de coligação entre os contratos.

Pode ser que em determinado negócio afastar-se-á não a totalidade do regime societário para resolução da sociedade, mas apenas uma ou algumas regras, enquanto em outros, o contrato será resolvido por regramento diverso de seu original.

Ao firmar o contrato de parceria imobiliária, prevendo dentro dessas diretrizes a constituição de determinada sociedade, para que as obras, contratações e negócios seguintes sejam realizados diretamente em nome da sociedade empresária, tem-se manifesta coligação contratual dependente entre esses contratos, especialmente do contrato social com a parceria imobiliária.

Isto porque, a constituição da sociedade decorre após as definições das regras e termos do negócio imobiliário. Neste caso, o contrato de parceria imobiliária seria o contrato-base do negócio, enquanto o contrato social a espécie de subcontrato, como consequência do primeiro e para o alcance do fim do negocial, em clara caracterização de coligação contratual (contrato-base ou contrato guarda chuva e subcontratos).

Decorre essa conclusão dos critérios interpretativos acima delineados, especialmente o fim contratual e a boa-fé objetiva, que quando aplicados à hipótese de coligação contratual, impõe propriamente dito a derrogação de determinado regramento em prol de outro, como meio de fazer cumprir o contratado e pretendido originalmente pelas partes, assim como evitar o enriquecimento ilícito e eventual aproveitamento de uma sobre outra, prestigiando o princípio da pacta sunt servanda.

Em face do alto grau de dependência do contrato social com a parceria imobiliária, terse-á o afastamento das regras de dissolução e liquidação da sociedade empresária, notadamente aqueles referentes a divisão de lucros ou perdas e exercício do poder de voto, devendo o negócio ser resolvido entre as partes com base nos dispositivos legais e contratuais aplicáveis à resolução do contrato-base.

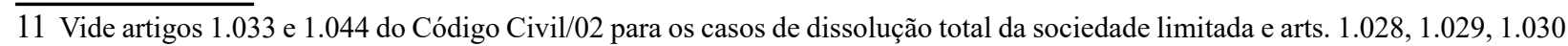
e 1.026 do Código Civil/02 para hipóteses de dissolução parcial. 
Nesse caso, as deliberações societárias, dissolução ordinária da sociedade ou nas regras de liquidação conforme artigos 1.031 e 1.102 e seguintes do Código Civil, deverão render-se ao que foi estabelecido no contrato principal, privilegiando as disposições contratuais do contrato de parceria imobiliária para os casos de resolução dos contratos coligados.

Comumente, quando da constituição da sociedade, não é objetivo das partes associarse por meio da constituição de sociedade limitada pelo simples interesse comum em exercer determinada atividade e se valer das prerrogativas empresariais e societárias. Apenas contrataram como forma legal de executar determinado empreendimento imobiliário contratado em parceria imobiliária, de modo que, a pretensão das partes sempre foi pelo sopesamento do pactuado sobre o legal. ${ }^{12}$

Da mesma forma que a declaração da resolução do contrato de parceria imobiliária implicará o retorno das partes ao estado anterior (status quo ante), a resolução do contrato social responsável pela constituição da sociedade como consequência da resolução da parceria, será também o retorno das partes a seu estado anterior. Tudo isso sem prejuízo das demais cominações legais e contratuais, como a indenização por perdas e danos por aquele que deu causa à rescisão. ${ }^{13}$

Por óbvio, que esta forma de faz lei entre as partes, razão pela qual não produzirá efeitos a terceiro de boa-fé, incidindo a res inter alios acta, aplicando-se estes as regras e efeitos do direito societário.

Dessa forma, tem-se que o inadimplemento de um dos contratantes quanto às obrigações assumidas em contrato de parceria imobiliária coligado ao contrato social de determinada sociedade, implicará na possibilidade de resolução de ambos os tipos contratuais, afastando as regras de direito societário para dissolução e liquidação de sociedade, especialmente quando o contrato social estiver em situação de maior dependência com os demais, como acontece no caso trabalhado.

\section{CONCLUSÃO}

\footnotetext{
12 Entretanto, não havendo disposições contratuais que regulamentem a dissolução do negócio, aplica-se ao caso as disposições do Código Civil a respeito do inadimplemento contratual de forma geral, vide artigo 475, segundo o qual "a parte lesada pelo inadimplemento pode pedir a resolução do contrato, se não preferir exigir-lhe o cumprimento, cabendo, em qualquer dos casos, indenização por perdas e danos" (BRASIL, 2002).

13 Este é o entendimento do STJ. O Min. Paulo de Tarso Sanseverino asseverou que a coligação contratual implica dependência dos contratos coligados, bem como que o contrato reputado como principal determina as regras a serem seguidas pelos demais a ele coligados, tratando inclusive da possibilidade de extensão de cláusula de um contrato sobre o outro. Confira-se a ementa: DIREITO CIVIL E PROCESSUAL CIVIL. ARBITRAGEM. CONTRATOS COLIGADOS. CONFLITO DECORRENTE DE CONTRATOS DE "SWAP" COLIGADOS A CONTRATO DE ABERTURA DE CRÉDITO COM CLÁUSULA COMPROMISSÓRIA. 1. Controvérsia em torno da (a) extensão da eficácia do compromisso arbitral constante do contrato principal de abertura e crédito aos contratos de swap, em face da coligação negocial, e da (b) validade da formação da corte arbitral. [...]. Nos contratos coligados, as partes celebram uma pluralidade de negócios jurídicos tendo por desiderato um conjunto econômico, criando entre eles efetiva dependência. [...] Reconhecida a coligação contratual, mostra-se possível a extensão da cláusula compromissória prevista no contrato principal os contratos de "swap", pois integrantes de uma operação econômica única. [...] No sistema de coligação contratual, o contrato reputado como sendo o principal determina as regras que deverão ser seguidas pelos demais instrumentos negociais que a este se ajustam, não sendo razoável que uma cláusula compromissória inserta naquele não tivesse seus efeitos estendidos aos demais (BRASIL, 2018a).
} 
O objetivo científico do trabalho e a ênfase dogmática da tese impõem a indicação das principais conclusões do estudo, que propôs e discutiu a resolução do contrato social por inadimplemento nos contratos coligados e o afastamento das regras de dissolução das sociedades limitadas nos negócios imobiliários de loteamento. Ao longo deste trabalho, demonstrou-se que na coligação contratual entre o contrato de parceria imobiliária e o contrato social de sociedade limitada, o inadimplemento dessas obrigações implicará na possibilidade de rescisão de todos os contratos coligados. Demonstrou-se que o descumprimento e rescisão do contrato de parceria imobiliária implicará na rescisão ao contrato de constituição da sociedade, contaminando-o pela inviabilidade do fim contratual objetivado pelas partes, uma vez que ambos os contratos cooperavam em conjunto como se uma unidade fossem.

Por fim, comprovou-se a possibilidade de resolução de ambos os tipos contratuais, afastando as regras de direito societário para dissolução e liquidação de sociedade, impondo sua derrogação, como meio de fazer cumprir o contratado e pretendido originalmente pelas partes, assim como evitar o enriquecimento ilícito e eventual aproveitamento de uma sobre outra, prestigiando o princípio da pacta sunt servanda.

\section{REFERÊNCIAS}

AGUIAR JUNIOR, Ruy Rosado de. Extinção dos contratos por incumprimento do devedor. 2. ed. Rio de Janeiro: Aide, 2004.

BERGSTEIN, Laís. Conexidade contratual, redes de contratos e contratos coligados. Revista dos Tribunais Online: Revista de Direito do Consumidor, São Paulo, v. 109, n. 229, p. 159-183, fev. 2017.

BRASIL. Lei n. 10.406, de 10 de Janeiro de 2002. Institui o Código Civil. Brasília: Presidência da República, 2002.

BRASIL. Supremo Tribunal de Justiça (3. Turma). REsp 0002163-90.2013.8.26.0100 SP 2015/0257748-2. Direito civil e processual civil. arbitragem. contratos coligados. conflito decorrente de contratos de "swap" coligados a contrato de abertura de crédito com cláusula compromissória. Relator: Min. Paulo de Tarso Sanseverino, 18 de Setembro de 2018a.

BRASIL. Supremo Tribunal de Justiça (4. Turma). AgInt no AREsp 0172568-

38.2009.8.07.0001 DF 2015/0065353-2. Execução fundada em contrato de confissão de dívida coligado a contrato de locação de imóvel. desconstituição do primeiro negócio que implica a do segundo. inexigibilidade do título executivo. interpretação de cláusulas contratuais. reexame de fatos e provas. impossibilidade. decisão mantida. recurso desprovido [...]. Relator: Min. Lázaro Guimarães, 17 de maio de 2018b.

BRASIL. Supremo Tribunal de Justiça (5. Turma). AgRg no REsp 1206723 / MG. Agravo regimental em resp. revisional locatícia. prevenção: art. $71, \S 3^{\circ}$. do ristj. nulidade relativa 
suscitada após o julgamento. recurso fundamentado. prequestionamento implícito. qualificação jurídica de atos/fatos. não incidência das súmulas 5 e 7/STJ. Cisão, acordo de acionistas e locação [...]. Relator: Min. Jorge Mussi, 17 de outubro de 2012. Disponível em: https://scon.stj. jus.br/SCON/SearchBRS?b=ACOR\&livre=@cdoc=\%271224595\%27. Acesso em: 14 ago. 2019.

KONDER, Carlos Nelson. Contratos conexos: grupos de contratos, redes contratuais e contratos coligados. Rio de Janeiro: Renovar, 2006.

LEONARDO, Rodrigo Xavier. Os contratos coligados, os contratos conexos e as redes contratuais. In: CARVALHOSA, Modesto. Tratado de direito empresarial. São Paulo: Revista dos Tribunais, 2016. p. ini-fin.

MARINO, Francisco Paulo de Crescenzo. Contratos coligados no direito brasileiro. São Paulo: Saraiva 2009.

MIRANDA, Francisco Cavalcanti Pontes de. Tratado de direito privado. Rio de Janeiro: Borsoi, 1962.t. 38.

VERÇOSA, Haroldo Malheiros Duclerc. Direito comercial: teoria geral do contrato. São Paulo: Revista dos Tribunais, 2014. v. 4.

Como citar: BRITO, Cristiano Gomes de; SILVEIRA, Mateus Martins da. A resolução do contrato social por inadimplemento nos contratos coligados e o afastamento das regras de dissolução da sociedade limitada nos negócios imobiliários de loteamento. Scientia luris, Londrina, v. 25, n. 3, p. 109-124, nov. 2021. DOI 10.5433/21788189.2021v25n3p109. ISSN: 2178-8189.

Recebido em 2020-02-02

Aprovado em 2021-09-22 